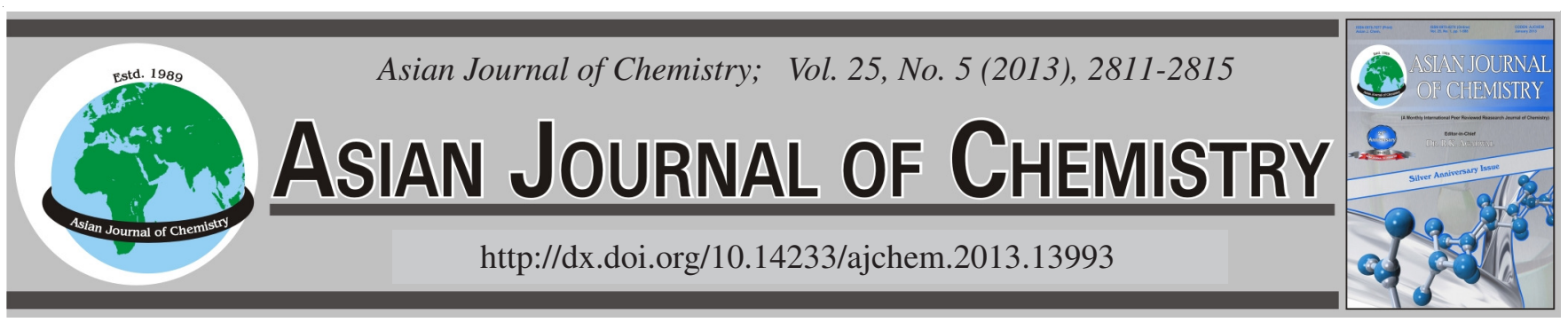

\title{
Removal of Tetracycline from Wastewater by Activated Carbons
}

\author{
J. CHEN ${ }^{1,2, *}$, J.P. WANG ${ }^{1,2}$, W.H. TAO ${ }^{1,2}$ and G.C. ZHANG ${ }^{1,2}$
}

${ }^{1}$ Jiangsu Provincial Key Laboratory of Coastal Wetland Bioresources and Environmental Protection, Yancheng, 224051 Jiangsu, P.R. China ${ }^{2}$ Department of Chemistry, Yancheng Teachers University, Yancheng 224051, Jiangsu, P.R. China

*Corresponding author: Fax: +86 515 88233188; Tel: +86 515 88233188; E-mail: keliernuonuo@ yahoo.cn

\begin{abstract}
The adsorption and desorption of tetracycline were investigated by static experiments, with two kinds of activated carbons employed as adsorbents. The related properties of the adsorbate and adsorbents were studied to support the adsorption mechanism exploration. The simulated wastewater was used to test the removal efficiency of tetracycline by activated carbon A. The results suggested that fairly strong $\mathrm{H}$-bonding exists between the functional groups of activated carbons and tetracycline and activated carbon is a promising adsorbent for tetracycline removal in the wastewater. The $\mathrm{HCl}$ solution can be used as desorption reagent.

Key Words: Adsorption, Desorption, Tetracycline, Activated carbon, Wastewater.
\end{abstract}

\section{INTRODUCTION}

Recently, the antibiotics in the environment have drawn more and more attention, because they might aid antibioticresistance of the microorganisms ${ }^{1}$. Generally, antibiotics are used as human infection medicine, veterinary medicine, husbandry and aquaculture growth promoters. As a group of broad-spectrum antibiotics, tetracyclines rank second throughout the world, concerning its production and usage ${ }^{2}$. Tetracyclines are poorly absorbed after intake, with about $25-75 \%$ of them leaving the organisms unmetabolized ${ }^{3}$. Thus, tetracyclines can be introduced into the environment ${ }^{3}$, during their extensive production and application. tetracyclines were once thought to be readily to decompose, but they have been detected in environmental samples, including soils ${ }^{1,4}$, surface waters ${ }^{5}$, groundwater and sediments ${ }^{2,5,6}$.

To develop effective treatment method, numerous studies have been conducted on tetracyclines. Some studies are about the adsorption properties of them on typical adsorbents. However, as a popular adsorbent, activated carbon has been less studied about the adsorption and desorption properties concerning tetracyclines in the wastewater. Thus, two kinds of activated carbons were employed as adsorbents and tetracycline as a typical sample of tetracyclines in present study to evaluate the adsorption of tetracycline and desorption properties, explore the associated adsorption mechanism and investigate the removal capacity of activated carbon in the simulated wastewater.

\section{EXPERIMENTAL}

Characteristics of the adsorbents and adsorbate: Activated carbon A was provided by Shanghai Activated Carbon Co. Ltd., (Shanghai, China) and activated carbon B was from Calgon (Filter 400). Each activated carbon was first pulverized into 100 mesh powders and then allowed soaking in $0.01 \mathrm{~mol} / \mathrm{L}$ $\mathrm{HCl}$ solution for $48 \mathrm{~h}$. The samples were then rinsed with deionized water to neutral, oven dried at $120^{\circ} \mathrm{C}$ and stored in a desicator before use.

The Boehm titration method was used to determine the concentrations of polar functional groups on activated carbons ${ }^{7}$. The $\mathrm{pH}$ drift method was employed to detect the $\mathrm{pH}_{\mathrm{PZC}}$ of the adsorbents ${ }^{8}$. And nitrogen adsorption and desorption measurements were conducted on a volumetric adsorption analyzer (ASAP 2020, Micromeritics Instrument Corp.), BET method and the Horvath-Kawazoe model were applied to evaluate the specific surface area and the pore size distribution of the samples, respectively ${ }^{9}$.

Important parameter, Kow was estimated for tetracycline. The deionized water had been boiled and cooled to room temperature in $\mathrm{N}_{2}$ airflow before use. Then the water was allowed to equilibrate with octanol for $48 \mathrm{~h}$. After separation, the octanol saturated water was used to prepare tetracycline solutions. Then the solutions were introduced to $100 \mathrm{~cm}^{3}$ glass bottles containing $60 \mathrm{~cm}^{3}$ water saturated octanol. After equilibrium (120 rpm, $25^{\circ} \mathrm{C}$, in dark), the $\mathrm{K}_{\text {ow }}$ of tetracycline was calculated based on the tetracycline concentration in the aqueous solution. 
Adsorption and desorption experiments: The adsorption isotherm was obtained by batch technique. The activated carbons were weighed and added to $50 \mathrm{~cm}^{3}$ polypropylene tubes containing $40 \mathrm{~cm}^{3}$ tetracycline solution with desired concentration $(\mathrm{I}=0.01 \mathrm{~mol} / \mathrm{L}, \mathrm{pH}=7)$. After equilibrium, $0.45 \mu \mathrm{m}$ membranes were used to separate the adsorbent particles from the solution. Concentration $\left(\mathrm{C}_{\mathrm{e}}\right)$ of tetracycline in the filtrate was then detected and adsorption capacity $\left(\mathrm{q}_{\mathrm{e}}\right)$ of carbons was calculated by mass balance.

Similar experiments were employed to evaluate the impacts of solution $\mathrm{pH}$, ionic strength and the coexisting substances in simulated wastewater on the adsorption. Typically, urea, $\mathrm{NaH}_{2} \mathrm{PO}_{4}, \mathrm{NaHCO}_{3}$, glucose and oxalic acid are added in the biosynthesis process of tetracycline. So the simulated wastewater of tetracycline was comprised with $1 \mathrm{mmol} / \mathrm{L}$ tetracycline, $7500 \mathrm{mg} / \mathrm{L}$ glucose, $2000 \mathrm{mg} / \mathrm{L}$ oxalic acid, $63 \mathrm{mg} / \mathrm{L}$ urea, $26 \mathrm{mg} / \mathrm{L} \mathrm{NaH} \mathrm{PO}_{4}, 50 \mathrm{mg} / \mathrm{L} \mathrm{NaHCO}$. In addition, the activated carbon $\mathrm{A}$ was chosen to test its performance under the simulated wastewater of tetracycline.

Desorption was operated following the adsorption experiments. Several desorption reagents were used, including $3 \mathrm{~mol} / \mathrm{L}$ $\mathrm{NaCl}$ at $\mathrm{pH} 8.5,1 \mathrm{~mol} / \mathrm{L} \mathrm{MgCl}_{2}$ at $\mathrm{pH} 8.5$ and $0.1 \mathrm{~mol} / \mathrm{L} \mathrm{HCl}$ solution $^{10}$.

Detection method: Concentration of tetracycline was analyzed by UV-VIS spectroscopy (GBC 916) at $280 \mathrm{~nm}$ wavelength and under the buffer of Mcllvaine solution ${ }^{10,11}$. The impacts from desorption reagents, coexisting substances in simulated wastewater on the detection were also assessed.

\section{RESULTS AND DISCUSSION}

Detection method: It was shown in Fig. 1, the linear relation between tetracycline concentration and the absorbance at $280 \mathrm{~nm}$ is applicable for the determination, even on the background of $1 \mathrm{~mol} / \mathrm{L} \mathrm{MgCl}_{2}$. No significant impact is found about the desorption reagents and coexisting substances (Fig. 2). Thus, spectrophotometer is reliable in this study with complicated components.

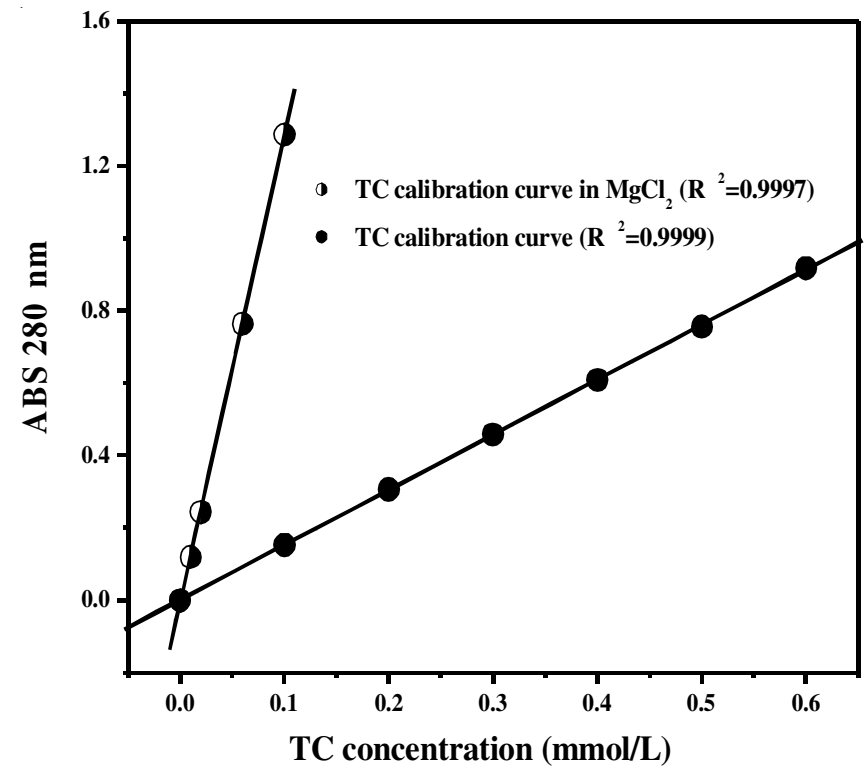

Fig. 1. Calibration curve for the determination of tetracycline (TC) by spectrophotometer

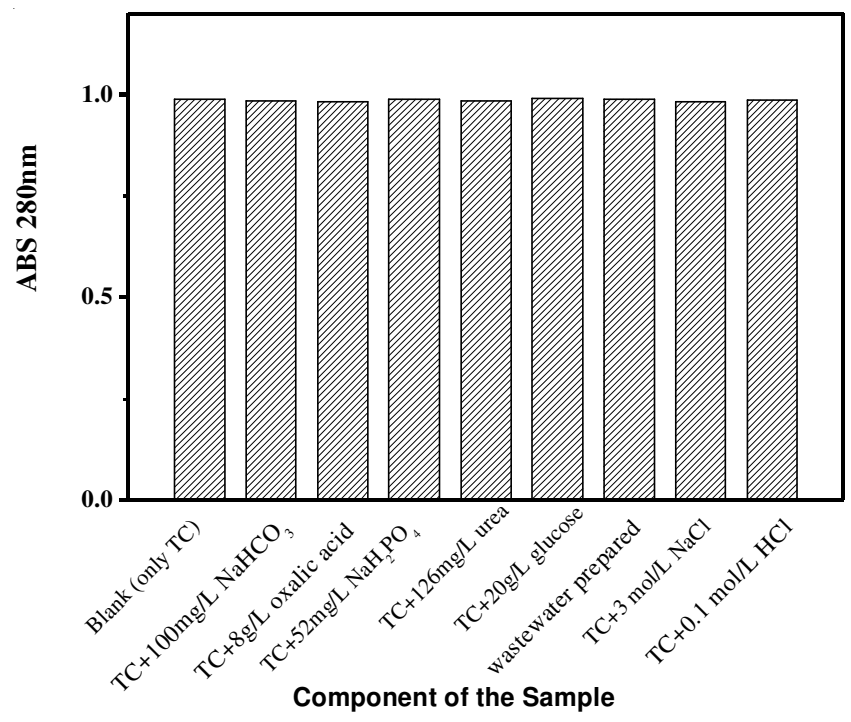

Fig. 2. Impacts from desorption reagents and coexisting substances on the detection

Characteristics of the adsorbents and adsorbate: Table1 provides the physical and chemical properties of activated carbon A and B. Total basic site concentration of A is about $70 \%$ of B's and total acidic site concentration of $\mathrm{A}$ is about 6 times of B's. The $\mathrm{pH}_{\mathrm{PZC}}$ is 5.0 for $\mathrm{A}$ and 8.2 for $\mathrm{B}$, respectively. Carbon A possesses a much higher BET specific surface area than $\mathrm{B}$ does. The pore diameter distribution for A locates in the ranges of both micropore and mesopore $(0-1,1-2,>2$ $\mathrm{nm})$, while that of $\mathrm{B}$ focus mainly in the range of micropore $(<2 \mathrm{~nm})$ (Fig. 3). Thus, it may be not readily for tetracycline, with a diameter about $0.83 \mathrm{~nm}, 1$ to head in some narrow channels of B.

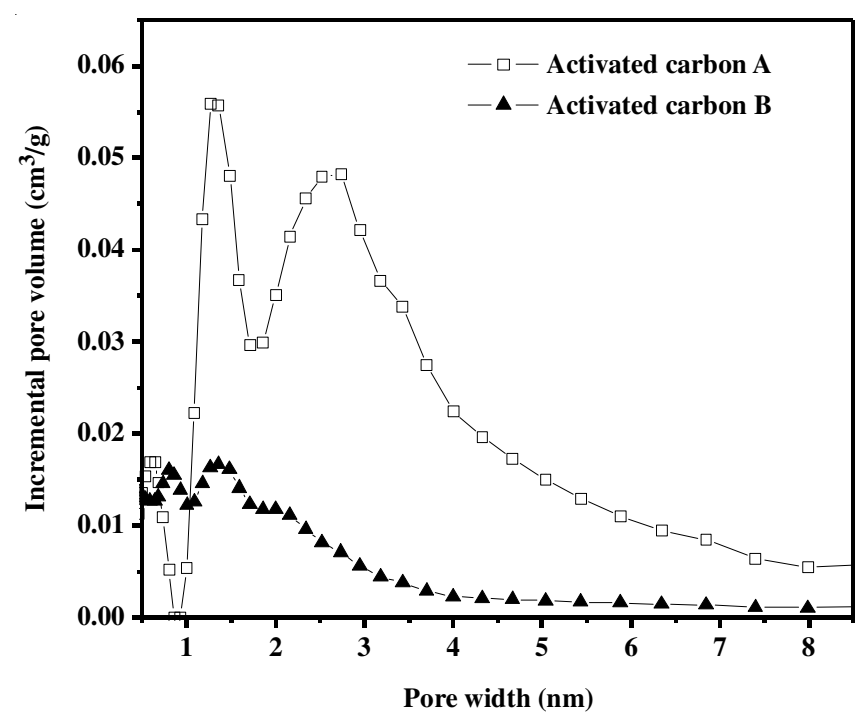

Fig. 3. Pore diameter distribution of activated carbon A and B

Fig. 4 gave tetracycline's speciation distribution. Tetracycline's charging property is complicated due to its triple protonated nature. tetracycline's major species is monovalent cation at $\mathrm{pH}<3.3$, neutral in $\mathrm{pH}$ 3.3-7.7, monovalent anion (-) in $\mathrm{pH}$ 7.7-9.7 and bivalent anion (2-) at $\mathrm{pH}>9.7$.

The $\mathrm{K}_{\mathrm{ow}}$ of tetracycline was also measured as a function of $\mathrm{pH}$ (Fig. 5). With the raised $\mathrm{pH}$, the $\mathrm{K}_{\mathrm{ow}}$ of tetracycline 
increases and achieves the maximum at about $\mathrm{pH}$ 5-5.5, then decreases. The trend is from the distribution of tetracycline's neutral species (Fig. 4). The results suggested, without net charge, the neutral species of tetracycline is more hydrophobic than the others.

\section{TABLE-1}

PHYSICAL AND CHEMICAL PROPERTIES OF ACTIVATED CARBON AND GRAPHITE

\begin{tabular}{lcc}
\hline & Carbon A & Carbon B \\
\hline Total basic sites concentration, $[\mathrm{mmol} / \mathrm{g}]$ & 0.25 & 0.34 \\
Total acidic sites concentration, $[\mathrm{mmol} / \mathrm{g}]$ & 0.82 & 0.14 \\
Phenolic, $[\mathrm{mmol} / \mathrm{g}]$ & 0.32 & 0.03 \\
Lactonic, $[\mathrm{mmol} / \mathrm{g}]$ & 0.32 & 0.04 \\
Carboxylic, $[\mathrm{mmol} / \mathrm{g}]$ & 0.18 & 0.07 \\
$\mathrm{pH}_{\text {PZC }}$ & 5.0 & 8.2 \\
Specific surface area, $\left[\mathrm{m}^{2} / \mathrm{g}\right]$ & 1884 & 894 \\
\hline
\end{tabular}

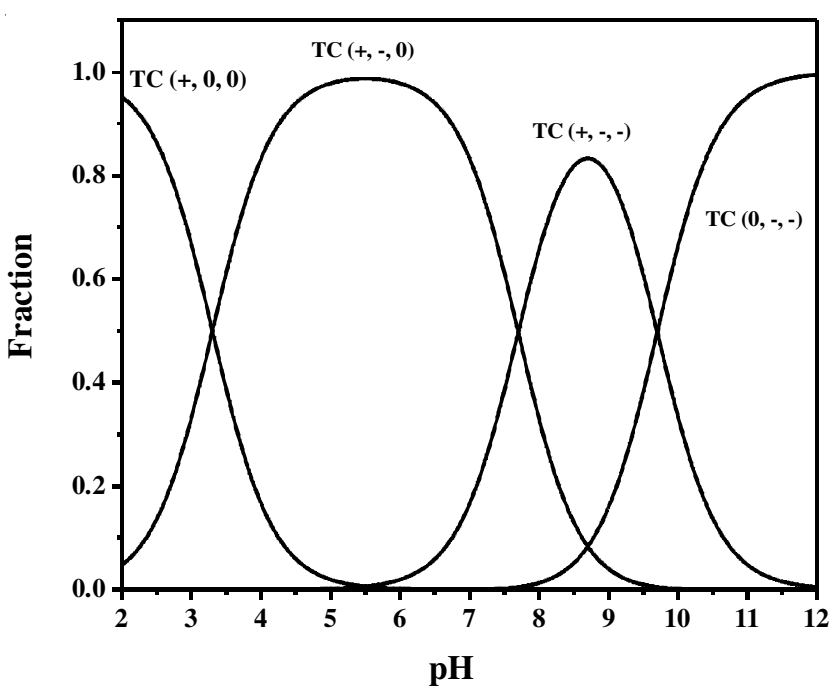

Fig. 4. Speciation distribution of tetracycline

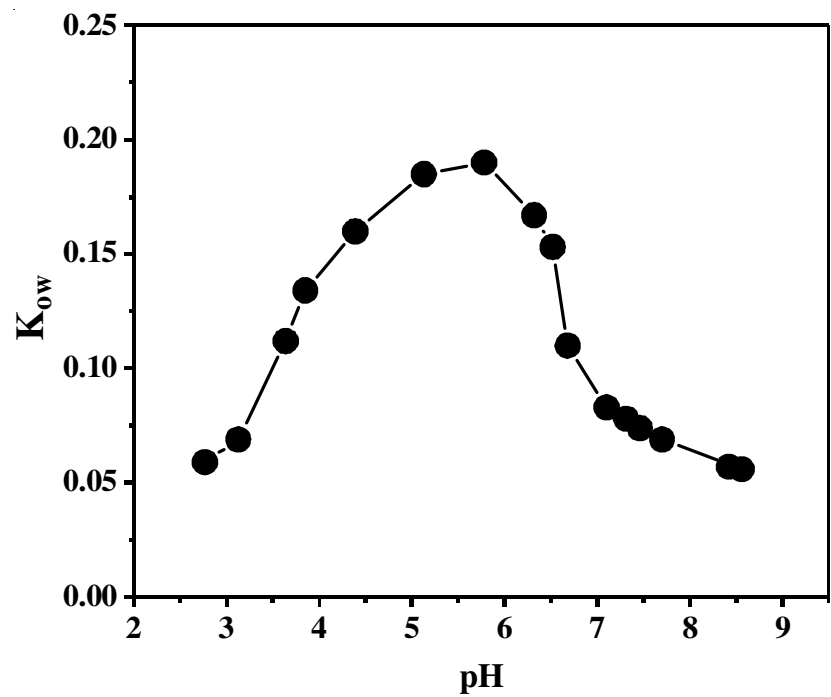

Fig. 5. $\mathrm{K}_{\text {ow }}$ of tetracycline on $\mathrm{pH}$

Adsorption and desorption experiments: It was shown in Fig. 6, the adsorption data for both activated carbons fit the Freundlich model, $\mathrm{q}=\mathrm{K}\left(\mathrm{C}_{\mathrm{e}}\right)^{\mathrm{n}}$, where $\mathrm{K}$ is the Freundlich coefficient, $\mathrm{C}_{\mathrm{e}}$ the aqueous-phase concentrations, $\mathrm{q}$ the solid- phase concentrations and $\mathrm{n}$ the Freundlich linearity index. The $\mathrm{n}$ value calculated is about 3.3 for $\mathrm{A}$ and 20 for $\mathrm{B}$. The departure of $\mathrm{n}$ from 1 suggests a heterogeneous interaction sites between the adsorbent and adsorbate ${ }^{13}$. The obtained index $1 / \mathrm{n}$ is also used to compare the adsorption affinity between $\mathrm{A}$ and $\mathrm{B}^{12}$. And the comparation shows the activated carbon B exhibits stronger adsorption strength than A does, because of the lower $1 / \mathrm{n}$ value about 0.05 .

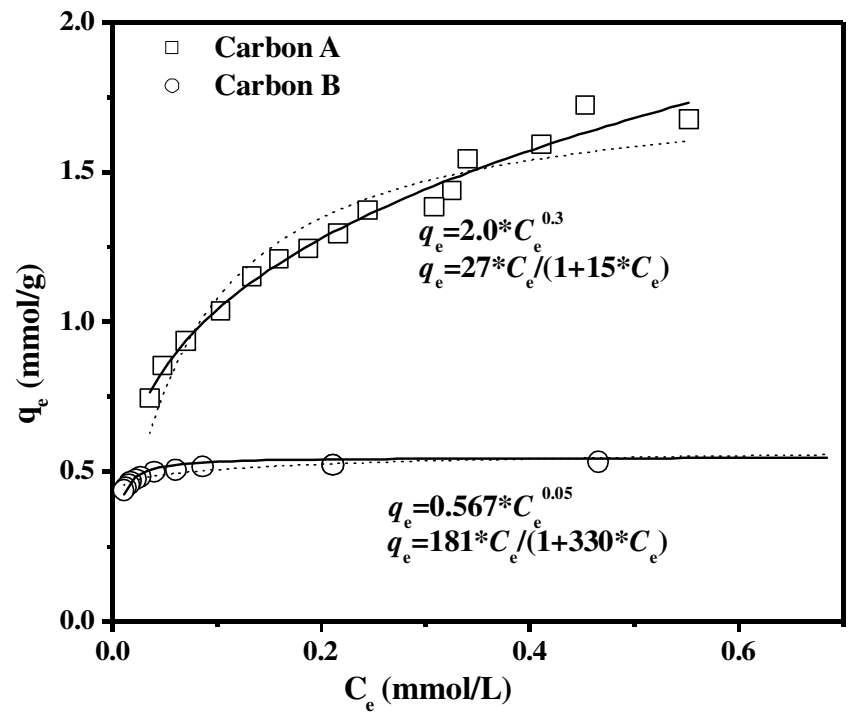

Fig. 6. Adsorption isotherms of tetracycline on activated carbon A and B

The Langmuir equation was used to calculate the adsorption capacities $\left(\mathrm{q}_{\mathrm{m}}\right)$ of the adsorbents ${ }^{12}$. The $\mathrm{q}_{\mathrm{m}}$ of activated carbon $\mathrm{A}$ is higher than $\mathrm{B}$. The difference may stem from three respects. First, the specific surface area of A is almost twice that of B. Second, the total functional groups concentration of $\mathrm{A}$ is higher than $\mathrm{B}$. Third, the pore diameter distribution for $\mathrm{B}$ hinders the entrance of the molecule of tetracycline to a certain extent.

The activated carbons exhibit much higher adsorption capacities, than bentonites, humic acid, peat, montmorillonites, graphite, hydrous oxides of $\mathrm{Al}$ and $\mathrm{Fe}$ (data and references are listed in Table-2). Other adsorbents also have high adsorption capacities for tetracycline, such as multi- or single- walled carbon nanotubes ${ }^{13}$. By a brief comparison, it could be found the adsorption capacities of tetracycline decrease in the order of single-walled carbon nanotubes $>$ activated carbon $\mathrm{A}>$ activated carbon $\mathrm{B}>$ multi-walled carbon nanotubes. While, at present, activated carbon may be more promising than the other adsorbents in the adsorption of tetracycline, because of its acceptable cost and considerable adsorption capacity.

It appeared in Fig. 7 that ionic strength does not affect the adsorption significantly, but the solution $\mathrm{pH}$ gives negative impacts. With fixed ionic strength and raised $\mathrm{pH} 3-9.8$, the adsorption capacity decrease more than $50 \%$ for carbon $\mathrm{A}$, while only slightly decrease for B.

Desorption experiments were operated with three reagents to probe the interaction between tetracycline and activated carbons (Fig. 8) ${ }^{10}$. It was found less than $5 \%$ of the adsorbed tetracycline was released by the first desorption reagent, $3 \mathrm{~mol} / \mathrm{L}$ $\mathrm{NaCl}$ solution, thus the nonspecific electrostatic interactions 
is not the primary adsorption mechanism. The second treatment was conducted with $1 \mathrm{~mol} / \mathrm{L} \mathrm{MgCl}_{2}$ solution, which has the same ionic strength with $3 \mathrm{~mol} / \mathrm{L} \mathrm{NaCl}$ solution, but contains $\mathrm{Mg}^{2+}$, which can form soluble complexes with tetracycline ${ }^{19}$. Only slight increase was observed in desorption rate. This result suggested the interaction between tetracycline and activated carbons is stronger than that exists between tetracycline and $\mathrm{Mg}^{2+}$. While, in the case of $0.1 \mathrm{~mol} / \mathrm{L} \mathrm{HCl}$ solution, almost $100 \%$ of the tetracycline was desorped, the desorption rate proved effective performance of strong acid.

\begin{tabular}{lccc}
\multicolumn{4}{c}{ TABLE-2 } \\
\multicolumn{3}{c}{$\begin{array}{c}\text { MAXIMUM ADSORPTION CAPACITIES OF TETRACYCLINE } \\
\text { ON DIFFERENT ADSORBENTS }\end{array}$} \\
\hline Adsorbent & $\mathrm{PH}$ & $\begin{array}{c}\mathrm{q}_{\mathrm{m}},\left[10^{-3}\right. \\
\mathrm{mol} / \mathrm{g}]\end{array}$ & Literatures \\
\hline Tannic acid-bentonite & 6.1 & 0.210 & 14 \\
Na-bentonite & 6.1 & 0.078 & 14 \\
Ca-bentonite & 6.1 & 0.200 & 14 \\
DDTMA-bentonite & 6.1 & 0.038 & 14 \\
Humic acid & 4.55 & 0.155 & 15 \\
Peat & 4.55 & 0.120 & 15 \\
Humic acid & 6.14 & 0.075 & 15 \\
Peat & 6.14 & 0.060 & 15 \\
Montmorillonite & 5.0 & 0.540 & 16 \\
Na-montmorillonite & 5.5 & 0.112 & 16 \\
Hydrous oxides of Al & 5.3 & 0.16 & 2 \\
Hydrous oxides of Fe & 5.3 & 0.12 & 2 \\
Activated carbon & 7.0 & 0.045 & 17 \\
Multi-walled carbon nanotubes & $7.0 \pm 0.2$ & 0.413 & 18 \\
Single-walled carbon nanotubes & 5.7 & 1.0 & 13 \\
Multi-walled carbon nanotubes & 6.0 & 0.1 & 13 \\
Activated carbon & 5.8 & 0.03 & 13 \\
Graphite & 5.8 & 0.01 & 13 \\
Activated carbon A & 7.0 & 1.795 & This work \\
Activated carbon B & 7.0 & 0.524 & This work \\
\hline
\end{tabular}

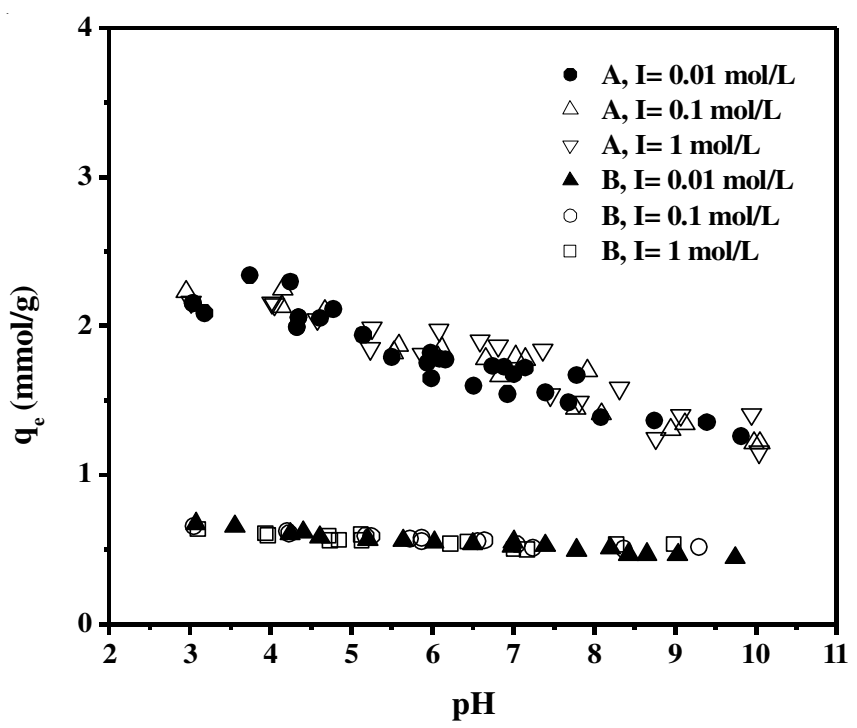

Fig. 7. Impacts of $\mathrm{pH}$ and ionic strength on tetracycline adsorption

Adsorption mechanism: By the results of the desorption, fairly strong interaction was suggested to exist between tetracycline and activated carbons. Therefore, several possible interactions were discussed based on the experiment results and the properties of tetracycline and the adsorbents.

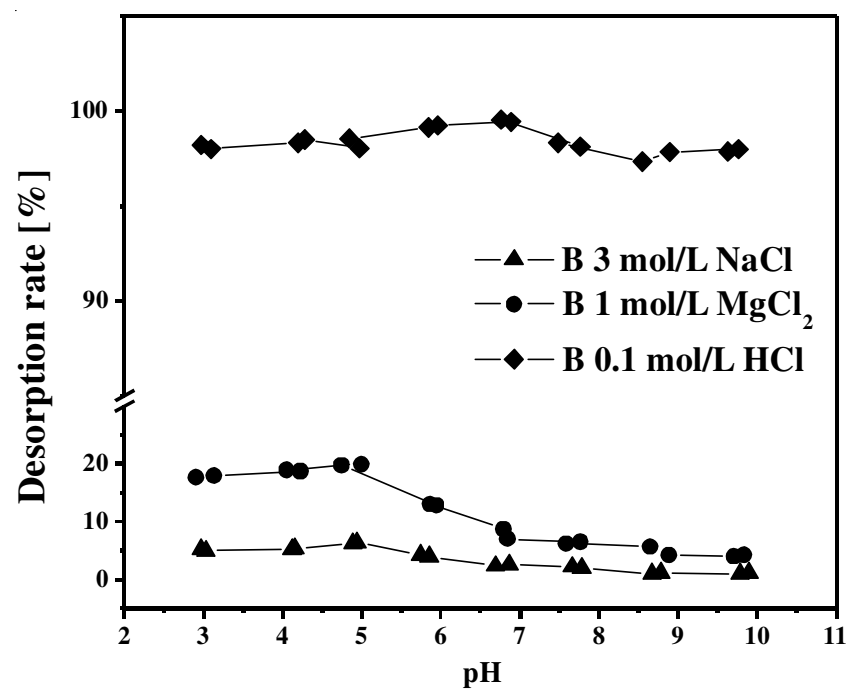

Fig. 8. Desorption rate of adsorbed tetracycline by different reagents

First, adsorption could not be caused by hydrophobic force. As the general trend of $\mathrm{K}_{\mathrm{ow}}$ (in Fig. 5) was quite different from the adsorption trend on $\mathrm{pH}$ (in Fig. 7). Furthermore, generally, increased ionic strength enhances the hydrophobic interaction between organic compound and adsorbent, but as shown in Fig. 7, there is no significant difference of adsorption capacities observed in a wide range of ionic strength (0.01-1 mol/L) on both carbon A and B. Hence, hydrophobic interaction would not be considered as the major driving force for the adsorption.

Second, electrostatic interaction was also investigated for possible adsorption mechanism. In general, higher ionic strength imposes negative impact on the adsorption stemming from electrostatic interaction ${ }^{20}$. While, the adsorption capacity is not a function of ionic strength. Hence, the adsorption can not caused mainly by electrostatic interaction. This conclusion is drawn based on the properties of activated carbons and tetracycline. As shown in Table-1, $\mathrm{pH}_{\mathrm{PZC}}$ is 5.0 for carbon $\mathrm{A}$ and 8.2 for carbon B, the net charge on carbon's surface should reverse at the corresponding $\mathrm{pH}_{\mathrm{PZC}}$. And the charging properties of tetracycline should change during the $\mathrm{pH}$ variation as shown in Fig. 4. In Fig. 7, there is no evidence on charges interaction in the monotonic decrease of adsorption capacities on $\mathrm{pH}$, while unexpected results were observed concerning electrostatic interaction. For example, the higher adsorption capacities presented under acidic condition, where both adsorbent and adsorbate charges alike. Therefore, the electrostatic interaction is not the main driving force for the adsorption. This conclusion is also supported by the results of desorption experiments employing $3 \mathrm{~mol} / \mathrm{L} \mathrm{NaCl}$ as desorption reagent ${ }^{10}$.

Third, H-bonding was proposed as the potential major driving force for tetracycline's adsorption on activated carbon. For tetracycline molecule has oxygen and nitrogen polar functional groups. It was indicated that there are $11 \mathrm{H}$-bond acceptors and $8 \mathrm{H}$-bond donors in each molecule of tetracycline ${ }^{4}$. They are expected to form strong hydrogen-bonding with polar functional groups (Table-1) on activated carbons ${ }^{15}$. These functional groups dissociate gradually with increasing aqueous $\mathrm{pH}$. The dissociation may cause the adsorption 
capacity decrease observed in Fig. 7. So, the results can be explained reasonably with $\mathrm{H}$-bonding interaction between functional groups on tetracycline molecule and activated carbon.

Performance of the activated carbons over simulated wastewater: In the Fig. 9a, b, c, the impacts on the adsorption capacity of activated carbons were presented, considering the coexisting substances in simulated wastewater. There are only slight fluctuations in the removal rate of tetracycline observed between 53-58\%. And only oxalic acid weakens the adsorption to a minor extent, while the other components including urea, $\mathrm{NaH}_{2} \mathrm{PO}_{4}, \mathrm{NaHCO}_{3}$ and glucose raise the removal rate of tetracycline. Even in the simulated wastewater, the activated carbon A performs stable. In addition, it was proved in Fig. 8 that $\mathrm{HCl}$ solution performs effective in the desorption process.

\section{Conclusion}

Activated carbons A and B give fairly high adsorption capacities of tetracycline and the adsorption capacities are not much impacted by ionic strength of the aqueous solutions, but negatively impacts are imposed by increasing aqueous $\mathrm{pH}$. The potential driving force for tetracycline to adsorb on activated carbon might be the $\mathrm{H}$-bonding between functional groups of activated carbon and the tetracycline. The activated

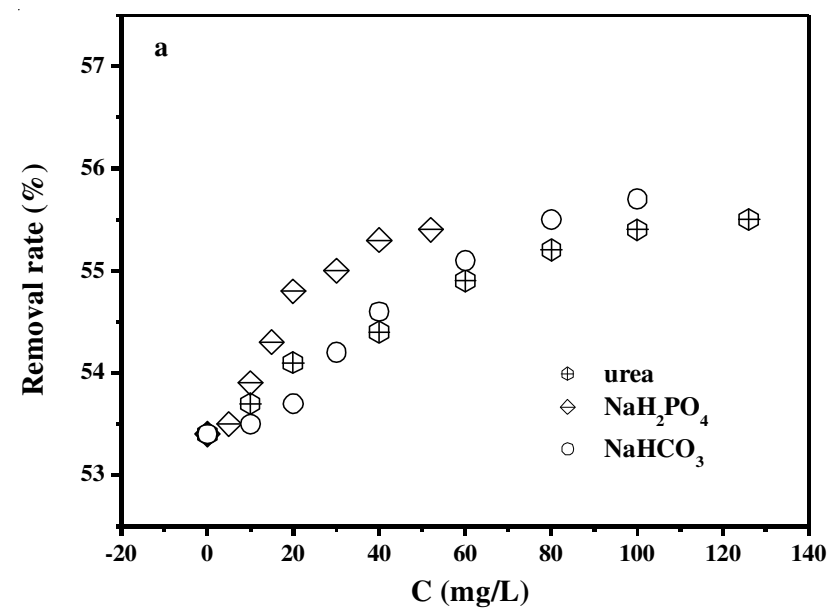

Fig. 9a. Influence of urea, $\mathrm{NaH}_{2} \mathrm{PO}_{4}$ and $\mathrm{NaHCO}_{3}$ on the removal rate of tetracycline

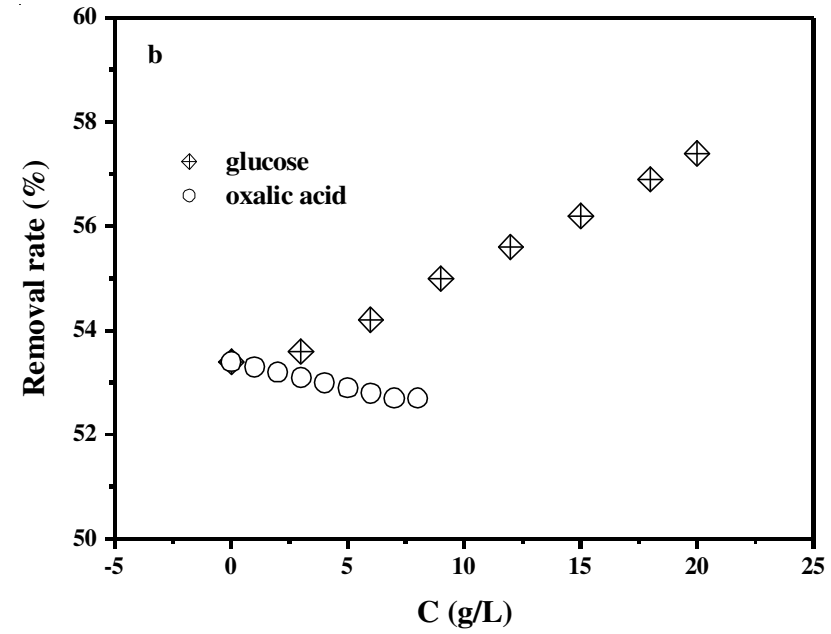

Fig. 9b. Influence of glucose and oxalic acid on the removal rate of tetracycline

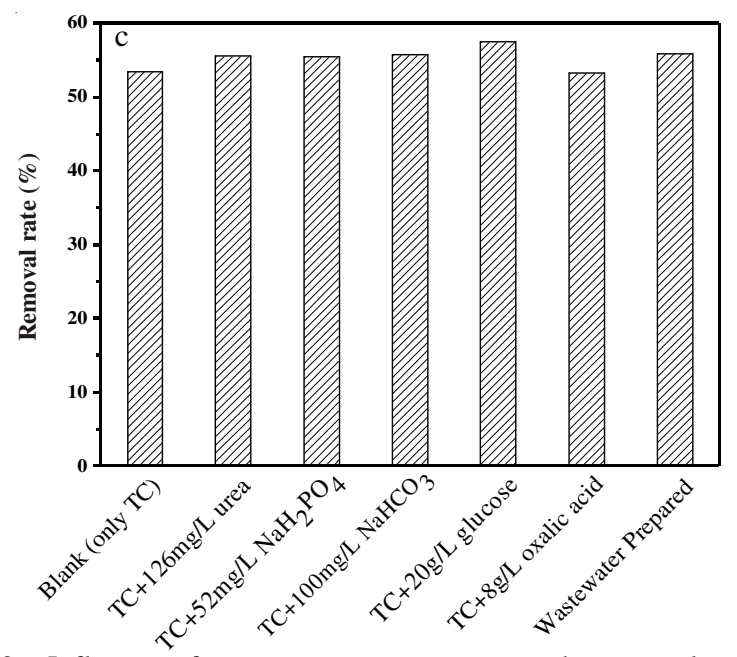

Fig. 9c. Influence of wastewater components on the removal rate of tetracycline

carbon is a promising adsorbent for tetracycline removal in the wastewater and $\mathrm{HCl}$ solution is an effective desorption reagent.

\section{ACKNOWLEDGEMENTS}

This project is supported by the Natural Science Foundation of the Jiangsu Higher Education Institutions of China (Grant No:12KJB610006) and the Natural Science Foundation of Jiangsu Province (Grant No. BK2012673). The authors expressed sincere gratitude to Jiangsu Provincial Key Laboratory of Coastal Wetland Bioresources and Environmental Protection (Grant Code: JLCBE 12030), Jiangsu Provincial Department of Science and Technology (Grant No. BK2010037) and the Specialized Research Fund for the Professor Program of Yancheng Teachers University (Grant No. 09YSYJB0202) for the financial support.

\section{REFERENCES}

1. R.A. Figueroa, A. Leonard and A.A. MacKay, Environ. Sci. Technol., 38, 476 (2004).

2. C. Gu and K.G. Karthikeyan, Environ. Sci. Technol., 39, 2660 (2005).

3. Z. Qiang, J.J. Macauley, M.R. Mormile, R. Surampalli and C.D. Adams, J. Agric. Food Chem., 54, 8144 (2006).

4. P. Kulshrestha, R.F. Giese and D.S. Aga, Environ. Sci. Technol., 38, 4097 (2004).

5. M.E. Lindsey, M. Meyer and E.M. Thurman, Anal. Chem., 73, 4640 (2001).

6. N.S. Simon, Environ. Sci. Technol., 39, 3480 (2005).

7. H.P. Boehm, Adv. Catal., 16, 179 (1966).

8. M.V. Lopez-Ramon, F. Stoeckli, C. Moreno-Castilla and F. CarrascoMarin, Carbon, 37, 1215 (1999).

9. F. Rouquerol, J. Rouquerol and K. Sing, Adsorption by powders and Porous Solids, Academic Press, London (1999).

10. R.A. Figueroa and A.A. MacKay, Environ. Sci. Technol., 39, 6664 (2005).

11. P.A. Blackwell, H.C.H. Lutzhoft, H.P. Ma, B. Halling-Sorensen, A.B.A. Boxall and P. Kay, J. Chromatogr. A, 1045, 111 (2004).

12. R.P. Han, J.J. Zhang, P. Han, Y.F. Wang, Z.H. Zhao and M.S. Tang, Chem. Eng. J., 145, 496 (2009).

13. L.L. Ji, W. Chen, L. Duan and D.Q. Zhu, Environ. Sci. Technol., 43, 2322 (2009).

14. B.B. Sithole and R.D. Guy, Water, Air, Soil Pollut., 32, 303 (1987).

15. B.B. Sithole and R.D. Guy, Water, Air, Soil Pollut., 32, 315 (1987).

16. J. Tolls, Environ. Sci. Technol., 35, 3397 (2001).

17. K.J. Choi, S.G. Kim and S.H. Kim, Environ. Technol., 29, 333 (2008).

18. P. Oleszczuk, B. Pan and B.S. Xing, Environ. Sci. Technol., 43, 9167 (2009).

19. B.T. Lunestad and J. Goksoyr, Dis. Aquat. Org., 9, 67 (1990).

20. D.L. Sparks, Environmental Soil Chemistry Academic Press, San Diego, edn 2 (2003). 